\title{
Self-Insurance and Self-Protection as Public Goods
}

\author{
Tim Lohse, Julio R. Robledo, and Ulrich Schmidt* \\ Leibniz Universität Hannover Discussion Paper No. 354 \\ ISSN 0949-9962 \\ December 13, 2006
}

\begin{abstract}
Many public goods like dams, fire departments, and lighthouses do not provide direct utility but act more as insurance devices against floods, fire, and shipwreck. They either diminish the probability or the size of the loss. We extend the public good model with this insurance aspect and generalize Samuelson's efficient allocation rule when self-insurance and self-protection expenditures are pure public goods. Some comparative static results with respect to changes in income and risk behavior are derived. As some of the sketched risks are insurable while some others are not, we introduce further the possibility of risk coverage by private market insurance. We analyze the interaction of such an insurance with the public good level, both for efficient provision and for private provision equilibria. It turns out that the levels of self-insurance and self-protection decrease when being privately provided. Moreover, it appears a strategic substitutability between the public good and market insurance which leads to an additional decline of the provision levels.
\end{abstract}

Keywords: Self-insurance, self-protection, efficient provision of public goods, private provision of public goods, market insurance

JEL Classification: G22, H41

${ }^{*}$ School of Economics and Management, Leibniz University Hannover, Königsworther Platz 1, 30167 Hannover, Germany, e-mail: lohse@fiwi.uni-hannover.de; Department of Economics, University of Vienna, Hohenstaufengasse 9, 1010 Vienna, Austria, e-mail: julio.robledo@univie.ac.at; Department of Economics, University of Kiel, Wilhelm-Selig-Platz 1, 24118 Kiel, Germany, e-mail: us@bwl.uni-kiel.de, respectively. We thank Martin McGuire, and conference participants at PET 2006 in Hanoi (Vietnam), Verein für Socialpolitik 2006 in Bayreuth (Germany), and ASSET 2006 in Lisbon (Portugal), as well as seminar participants at the Universities of Innsbruck and Linz (Austria) for helpful comments. All errors and omissions are our own. 


\section{Introduction}

The efficient provision level of a pure public good is characterized by the well-known Samuelson condition (Samuelson 1954, 1955). Very often, there is no social planner or superior authority with the power or the information about the willingness to pay for the public good, and the public good has to be provided privately. Seminal reference on this private provision games are Cornes and Sandler (1984) and Bergstrom et al. (1986). They show the existence of private provision equilibria leading to a suboptimal provision level of the public good.

The standard literature (for a survey, see e.g. Cornes and Sandler, 1996) as well as all more recent models always assume, irrespective whether the public good is provided publicly or privately, that the level of the public good is a direct functional argument of the individual's utility function. This assumption is not always realistic: Many of the standard textbook examples of public goods like lighthouses, dikes, national armies or fire stations do not provide direct utility, but act rather as an insurance device.

The literature on the private provision of public goods has considered the case of provision under uncertainty, suggesting that uncertainty reduces the free-riding incentive depending on the properties of the third derivatives of the utility function. ${ }^{1}$ But the uncertainty in this setting is about the contributions of the other individuals or about their contribution behavior, and not about the utility of the public good itself. Lighthouses, dikes or national armies diminish the probability of a loss caused by shipwreck, floods or war. Likewise, fire departments also do not increase the utility of an individual by their sheer existence, but exclusively lower the size of the loss in a fire case. Thus, these public goods, following Ehrlich and Becker (1972), can be considered as insurance devices which decrease the size of the loss (self-insurance) and those which reduce the probability of a loss (self-protection). Our paper develops a model in which self-insurance and self-protection are not, as in Ehrlich and Becker (1972), private goods, but public goods with non-rival consumption. We develop conditions characterizing the efficient provision level of those public goods and analyze the provision level when self-insurance and self-protection as public goods are privately provided. Moreover, we investigate for both cases the impact of the presence of market insurance on the provision level of the public good. Our results show that the optimal level of the public good decreases if fair market insurance is available. It is

\footnotetext{
${ }^{1}$ See the contributions of Austen-Smith (1980), Sandler et al. (1987), Gradstein et al. (1993), among others.
} 
well-known that individuals will buy full insurance if insurance premiums are fair (Mossin, 1968). In this case, the optimal level of the public good will maximize expected wealth; i. e., it equals the optimal level for risk neutral individuals which is lower than the optimal level for risk averse subjects. Consequently, the state should invest more in public selfinsurance and self-protection in case of events which are not insurable, e.g. wars or nuclear incidents. When we analyze public self-protection in the presence of market insurance, we realistically assume that the level of the public good can be observed by insurers and hence reduces premiums in an actuarial fair way. This means that a moral hazard problem does not occur in the case of public self-protection, which may be an advantage compared to private self-protection efforts which are often not observable.

The paper proceeds as follows. The next section presents the model and the modified Samuelson conditions for the efficient provision level of self-insurance and self-protection as public goods. The comparative statics results for changes in income and risk behavior are presented in section 3. In section 4 the additional possibility of a market insurance is introduced and the relating efficiency conditions are derived. Section 5 presents the Nash equilibria when the self-insurance and self-protection are privately provided public goods. Section 6 introduces the optimal individual choice when public self-insurance and self-protection can be complemented or substituted with market insurance. Section 7 summarizes the results and concludes.

\section{Efficient provision of the public good}

\subsection{Self-insurance as a public good}

Consider an economy with $n$ individuals having a concave von Neumann utility function $u$. There are two possible states of the world, 1 and 2 . With probability $1-p$ there is no loss, while with the residual probability $p$ a uniform loss $L$ occurs for all individuals. The size of the loss $L$ depends on the level of the public good $G, L(G)$, where $G$ is the sum of all private contributions to the public good; i. e., $G=\sum_{i=1}^{n} g^{i}$. One can think, for instance, that the loss of a fire depends on the provision level of fire departments. ${ }^{2}$ It is reasonable to assume that a high level of the public good reduces the size of the loss with diminishing productivity: $L^{\prime}(G)<0$ and $L^{\prime \prime}(G)>0$. We further assume that it is worthwhile to invest in loss reduction, i. e. $\lim _{G \rightarrow 0} L^{\prime}(G) \rightarrow-\infty$.

\footnotetext{
${ }^{2}$ Orszag and Stiglitz (2002) have analyzed the optimal provision of fire departments as public goods.
} 
Each individual $i=1, \ldots, n$ is endowed with income $m_{i}$ which she may spend on increasing the level of the public good $G$ with a non-negative contribution $g_{i} \geq 0$. For convenience, we set the marginal cost of contributing to the public good to 1 . This leads to the following state contingent income levels:

$$
\begin{aligned}
& y_{i 1}=m_{i}-g_{i} \\
& y_{i 2}=m_{i}-g_{i}-L(G),
\end{aligned}
$$

where $y_{i j}$ denotes the income of individual $i$ in state $j$. It never pays to spend all income on self-insurance effort, i. e. $\lim _{y \rightarrow 0} u^{\prime}(y) \rightarrow \infty$. The individual $i$ maximizes her expected utility given by

$$
E U_{i}\left(g_{i}, G\right)=p U\left(m_{i}-g_{i}-L(G)\right)+(1-p) U\left(m_{i}-g_{i}\right)=p U_{i 2}+(1-p) U_{i 1}
$$

Note that $g_{i}=G-G_{-i}$ where $G_{-i}$ is the level provided by all other contributors but $i$; i. e., $G_{-i}=\sum_{j=1, j \neq i}^{n} g_{j}$.

Suppose first that $n=1$; i. e., that $G_{-i}=0$ and $G=g_{1}$. The only individual maximizes her expected utility (3) by her choice of $G$ leading to the first-order condition

$$
\frac{d E U_{1}}{d G}=p U_{12}^{\prime}\left(-1-L^{\prime}(G)\right)+(1-p) U_{11}^{\prime}(-1)=0
$$

which can be rearranged to

$$
\frac{p}{1-p} \frac{U_{12}^{\prime}}{U_{11}^{\prime}}=\frac{1}{-1-L^{\prime}(G)} .
$$

The left hand side of (5) is the marginal rate of substitution between state 1 and state 2 , e. g. the marginal willingness to pay for the loss reduction via $G$ in state 2 by accepting an income reduction in state 1 which is (in absolute value) the slope of the individual's indifference curve. The right hand side is the "cost" of this loss reduction. Alternatively, one can rearrange condition (5) to express the marginal benefit and the marginal cost with respect to $G$ :

$$
\left(-L^{\prime}(G)\right) p U_{12}^{\prime}=(1-p) U_{11}^{\prime}+p U_{12}^{\prime}=: E U_{1}^{\prime}
$$

The left hand side of (6) is the marginal benefit of an additional investment in the public good to reduce the size of the loss, the marginal utility of the public self-insurance multiplied with the productivity of $G$ at reducing the loss. This loss reduction is only effective in the bad state of the world, and therefore it has to be multiplied with its probability $p$. The right hand side is the marginal cost of this additional spending on $G$, which accrues in 
both states of the world. We will denote this marginal expected utility with $E U_{i}^{\prime}$. The second-order condition is fulfilled by the assumptions on $u$ and $L$.

The first-best, Pareto efficient outcome for $n>1$ is found when the expected utility level of individual $1 E U_{1}$ is maximized, given the restrictions that individuals 2 to $n$ obtain given expected utility levels $\overline{E U}_{j}, j=2, \ldots, n$ and that $G=\sum_{i=1}^{n} g_{i}$. The resulting Lagrangian for this problem is

$$
\mathcal{L}=E U_{1}+\sum_{j=2}^{n} \mu_{j}\left(E U_{j}-\overline{E U}_{j}\right)+\lambda\left(G-\sum_{i=1}^{n} g_{i}\right)
$$

The first-order conditions with respect to $G$ and $g_{i}$ are

$$
\begin{aligned}
& \frac{\partial \mathcal{L}}{\partial G}=\sum_{i=1}^{n} \mu_{i} p U_{i 2}^{\prime}\left(-L^{\prime}\left(G_{S I}^{*}\right)\right)+\lambda=0 \\
& \frac{\partial \mathcal{L}}{\partial g_{i}}=\mu_{i}\left((1-p) U_{i 1}^{\prime}+p U_{i 2}^{\prime}\right)+\lambda=0, \quad \text { for } i=1, \ldots, n,
\end{aligned}
$$

where $\mu_{1}=1$. The superscript $*$ denotes the efficient level of the public good, and the subscript $S I$ refers to self-insurance. Solving each of the $n$ equations (9) for $\mu_{i}$, substituting into (8) and canceling out $\lambda$, we obtain

\section{Proposition 1 (Efficient level of public self-insurance)}

The Pareto efficient level of a public good $G$ which acts as a self-insurance device is given by the following modified Samuelson condition:

$$
\sum_{i=1}^{n} \frac{p U_{i 2}^{\prime}\left(-L^{\prime}\left(G_{S I}^{*}\right)\right)}{E U_{i}^{\prime}}=1
$$

The left hand side is the willingness to pay for the public good $G$ : the marginal positive effect of an additional unit of $G$, measured in units of forgone income in both states of the world (marginal expected utility $E U_{i}^{\prime}$ ). Since an additional unit of $G$ benefits all individuals, it is the sum of the marginal willingness to pay for public self-insurance of all individuals which should equal the marginal cost of an additional unit of $G$.

\subsection{Self-protection as a public good}

In the following, we alter the model above and assume now that the public good $G$ reduces the probability of the loss. The size of the loss $L$ is fixed and uniform for all individuals. The probability of a bad state can be reduced by contributing to the public good and will be denoted by $p(G)$. For the relationship between the public good level and the probability 
of the bad state, we again assume realistically that increasing $G$ reduces its probability with diminishing returns: $p^{\prime}(G)<0$ and $p^{\prime \prime}(G)>0$.

As before, the first-best, Pareto efficient outcome is found when the expected utility level of individual $1 E U_{1}$ is maximized given the restrictions that individuals 2 to $n$ obtain given expected utility levels $\overline{E U_{j}}, j=2, \ldots, n$ and that $G=\sum_{i=1}^{n} g_{i}$. The resulting Lagrangian for the self-protection problem is

$$
\begin{aligned}
\mathcal{L}= & p(G) U\left(m_{1}-g_{1}-L\right)+(1-p(G)) U\left(m_{1}-g_{1}\right)+ \\
& \sum_{j=2}^{n} \mu_{j}\left(p(G) U\left(m_{j}-g_{j}-L\right)+(1-p(G)) U\left(m_{j}-g_{j}\right)-\overline{E U}_{j}\right)+\lambda\left(G-\sum_{i=1}^{n} g_{i}\right) \\
= & p(G) U_{12}+(1-p(G)) U_{11}+ \\
& \sum_{j=2}^{n} \mu_{j}\left(p(G) U_{j 2}+(1-p(G)) U_{j 1}-\overline{E U}_{j}\right)+\lambda\left(G-\sum_{i=1}^{n} g_{i}\right)
\end{aligned}
$$

and leads to the following first-order conditions with respect to $G$ and $g_{i}$ :

$$
\begin{aligned}
\frac{\partial \mathcal{L}}{\partial G} & =\sum_{i=1}^{n} \mu_{i} p^{\prime}\left(G_{S P}^{*}\right)\left(U_{i 2}-U_{i 1}\right)+\lambda=0 \\
\frac{\partial \mathcal{L}}{\partial g_{i}} & =\mu_{i}\left(p\left(G_{S P}^{*}\right) U_{i 2}^{\prime}+\left(1-p\left(G_{S P}^{*}\right)\right) U_{i 1}^{\prime}\right)+\lambda=0, \quad \text { for } i=1, \ldots, n,
\end{aligned}
$$

where again $\mu_{1}=1$, the superscript $*$ stands for efficiency and the subscript $S P$ for self-protection. We obtain analogously to the self-insurance case

\section{Proposition 2 (Efficient level of public self-protection)}

The Pareto efficient level of a public good $G$ which acts as a self-protection device is given by the following modified Samuelson condition:

$$
\sum_{i=1}^{n} \frac{p^{\prime}\left(G_{S P}^{*}\right)\left(U_{i 2}-U_{i 1}\right)}{E U_{i}^{\prime}}=1 .
$$

This condition resembles again the Samuelson condition. Since the reduction in the probability of the loss accrues to all individuals, the left hand side is the sum of the marginal willingness to pay of all individuals for this reduction. The marginal willingness to pay is the difference in utility between both states of the world, weighted with the marginal change in the probability of the loss and measured in units of forgone income as given by the marginal expected utility $E U_{i}^{\prime}$ in the denominator. This sum of marginal benefits must equal the right hand side, which is the marginal cost of the public good. 
In contrast to the self-insurance case, where concavity of $U$ is sufficient for the first-order condition to determine a maximum of expected utility, the second-order condition with self protection is more complicated (see Ehrlich and Becker, 1972, for the case when selfinsurance is a private good). While self-insurance involves redistributing income from the good state of the world to the bad state, self-protection just reduces the probability of the loss without redistributing income. Since the absolute size of the loss does not change, self-protection expenditures increase the relative size of the loss. Thus, concavity of $U$ (decreasing marginal utility of income) is not sufficient to ensure a maximum of (11). In the following, we assume that the second-order condition is fulfilled and therefore conditions (14) describe the Pareto efficient outcome.

\section{Comparative statics of income and risk behavior}

\subsection{The effect of income}

In the spirit of Wagner's Law - the law of increasing expansion of public expenditure, and particularly state activities, as per capita real income grows - we are going to analyze the comparative statics of the first best results given in Propositions 1 and 2. To derive how the efficient provision level of the public good $G$ reacts to a change in income $m_{i}, \frac{d G}{d m_{i}}$ we denote with FOC the first-order condition and get

$$
\frac{d G}{d m_{i}}=-\frac{\frac{\partial F O C}{\partial m_{i}}}{\frac{\partial F O C}{\partial G}} .
$$

If the first-order conditions fulfill the sufficient conditions for a maximum, the denominator is negative. Therefore, the sign of $\frac{d G}{d m_{i}}$ depends uniquely on the sign of $\frac{\partial F O C}{\partial m_{i}}$.

\section{(i) The case of self-insurance}

Consider the first-order condition FOC (10) and take the partial derivative with respect to income $i$ :

$$
\begin{aligned}
\frac{\partial F O C}{\partial m_{i}} & =\sum_{i=1}^{n}\left(\frac{E U_{i}^{\prime} p U_{i 2}^{\prime \prime}\left(-L^{\prime}\left(G_{S I}^{*}\right)\right)-p U_{i 2}^{\prime}\left(-L^{\prime}\left(G_{S I}^{*}\right)\right) E U_{i}^{\prime \prime}}{E U_{i}^{\prime 2}}\right) \\
& =p\left(-L^{\prime}\left(G_{S I}^{*}\right)\right) \sum_{i=1}^{n}\left(\frac{E U_{i}^{\prime} U_{i 2}^{\prime \prime}-U_{i 2}^{\prime} E U_{i}^{\prime \prime}}{E U_{i}^{\prime 2}}\right)
\end{aligned}
$$

It suffices to consider only one addend. The sign of each addend depends on the sign of 
the numerator

$$
\begin{aligned}
E U_{i}^{\prime} U_{i 2}^{\prime \prime}-U_{i 2}^{\prime} E U_{i}^{\prime \prime} & =\left(p U_{i 2}^{\prime}+(1-p) U_{i 1}^{\prime}\right) U_{i 2}^{\prime \prime}-U_{i 2}^{\prime}\left(p U_{i 2}^{\prime \prime}+(1-p) U_{i 1}^{\prime \prime}\right) \\
& =(1-p)\left(U_{i 1}^{\prime} U_{i 2}^{\prime \prime}-U_{i 2}^{\prime} U_{i 1}^{\prime \prime}\right) \\
& =(1-p) U_{i 1}^{\prime} U_{i 2}^{\prime}\left(\frac{U_{i 2}^{\prime \prime}}{U_{i 2}^{\prime}}-\frac{U_{i 1}^{\prime \prime}}{U_{i 1}^{\prime}}\right) \\
& =\underbrace{(1-p) U_{i 1}^{\prime} U_{i 2}^{\prime}}_{(+)}\left(A_{1}-A_{2}\right),
\end{aligned}
$$

where $A_{1}$ and $A_{2}$ denote the Arrow-Pratt measures of absolute risk aversions calculated at the state contingent income levels $y_{1}$ and $y_{2}: A_{j}:=-\frac{U_{i j}^{\prime \prime}}{U_{i j}^{\prime}}$ (Pratt, 1964). Thus, the effect of an income change on the efficient public level of self-insurance depends on how the Arrow-Pratt measure of absolute risk aversion changes with income:

\section{Proposition 3 (Effect of income on public self-insurance)}

If income rises, the efficient provision of public self-insurance

1. stays constant for a constant absolute risk aversion (CARA); i. e., $A^{1}=A^{2}$.

2. increases for an increasing absolute risk aversion (IARA); i. e., $A^{1}>A^{2}$.

3. decreases for a decreasing absolute risk aversion (DARA); i. e., $A^{1}<A^{2}$.

\section{(ii) The case of self-protection}

Assuming the second-order condition holds, we can proceed in an analogous way and determine the sign of

$$
\frac{\partial F O C(14)}{\partial m_{i}}=\sum_{i=1}^{n}\left(\frac{p^{\prime}\left(G_{S P}^{*}\right)\left[E U_{i}^{\prime}\left(U_{i 2}^{\prime}-U_{i 1}^{\prime}\right)-E U_{i}^{\prime \prime}\left(U_{i 2}-U_{i 1}\right)\right]}{E U_{i}^{\prime 2}}\right) .
$$

It turns out that the effect is ambiguous in the case of self-protection. To see this, consider one addend that can be rearranged in the following way:

$$
\frac{p^{\prime}\left(G_{S P}^{*}\right)\left(U_{i 2}^{\prime}-U_{i 1}^{\prime}\right)}{E U_{i}^{\prime}}-\frac{E U_{i}^{\prime \prime}}{E U_{i}^{\prime}} \frac{p^{\prime}\left(G_{S P}^{*}\right)\left(U_{i 2}-U_{i 1}\right)}{E U_{i}^{\prime}}
$$

The minuend is the change in the marginal benefit of $G$ caused by an increase of $m$ and is measured in units of foregone consumption represented by the residual income $m . p^{\prime}$ is negative, and, for an increase in $m, u_{2}$ increases more than $u_{1}$ does. Hence, the difference in marginal utility between the bad and the good state of the world decreases, but remains positive. However, the first term of the subtrahend displays the change in marginal utility 
costs of providing $G$ due to an increase in $m$ and is measured as well in units of the marginal benefit of $m$. This change is negative because marginal utility decreases in both states as $m$ increases. The change of costs is weighted by the marginal willingness to pay for the public good as it is characterized by the second term. To sum up, an unambiguous increase in $G$ occurs only if an increase in $m$ reduces marginal cost more than it reduces marginal benefit. ${ }^{3}$

\subsection{The effect of risk behavior}

Another important effect is the role of the behavior towards risk. How does the optimal level of provision of the public good change when society becomes more risk-averse? For answering this question, we adapt an approach of Dionne and Eeckhoudt (1985).

\section{(i) The case of self-insurance}

Suppose the utility function $V$ represents more risk-averse preferences than the utility function $U$. Then, there exists a function $f$ with $f^{\prime}(\cdot)>0$ and $f^{\prime \prime}(\cdot)<0$ such that $V=f(U)$ (Pratt, 1964). Under the same endowed incomes and size of loss as in section 2.1, the appropriate first-order condition for the more risk averse society is given by

$$
\sum_{i=1}^{n} \frac{p f^{\prime}\left(U_{i 2}\right) U_{i 2}^{\prime}\left(-L^{\prime}(\tilde{G})\right)}{p f^{\prime}\left(U_{i 2}\right) U_{i 2}^{\prime}+(1-p) f^{\prime}\left(U_{i 1}\right) U_{i 1}^{\prime}}=1
$$

and characterizes the efficient level $\tilde{G}_{S I}^{*}$, where the tilde denotes the increased risk aversion. Now, we substitute the original $G_{S I}^{*}$ in (20). Clearly, if

$$
\sum_{i=1}^{n} \frac{p f^{\prime}\left(U_{i 2}\right) U_{i 2}^{\prime}\left(-L^{\prime}\left(G_{S I}^{*}\right)\right)}{p f^{\prime}\left(U_{i 2}\right) U_{i 2}^{\prime}+(1-p) f^{\prime}\left(U_{i 1}\right) U_{i 1}^{\prime}}>1
$$

holds, then $\tilde{G}_{S I}^{*}>G_{S I}^{*}$ follows. The intuition of (21) is straightforward. The current level of the public self-insurance is $G_{S I}^{*}$, and the cost of an additional unit of $G$ is 1 . But as society has become more risk-averse, the sum of the marginal willingness to pay for public self-insurance of all individuals exceeds the additional cost. Hence, the efficient level of the provision of the public good must be higher than $G_{S I}^{*}$.

\section{(ii) The case of self-protection}

\footnotetext{
${ }^{3}$ See Ihori and McGuire (2007) for an extended analysis of the question whether the public good is normal or inferior. In our notation, $G$ would be an inferior good if, due to an increase in $m$, the decline of the marginal benefit is larger than the reduction of the marginal cost.
} 
For an increase in risk-aversion, consider again a concave transformation as described above. The resulting first-order condition is

$$
\sum_{i=1}^{n} \frac{p^{\prime}\left(\tilde{G}_{S P}^{*}\right)\left(f\left(U_{i 2}\right)-f\left(U_{i 1}\right)\right)}{p f^{\prime}\left(U_{i 2}\right) U_{i 2}^{\prime}+(1-p) f^{\prime}\left(U_{i 1}\right) U_{i 1}^{\prime}}=1
$$

and gives $\tilde{G}_{S P}^{*}$. Now, substitute $G_{S P}^{*}$ in $(22)$. Then, if

$$
\sum_{i=1}^{n} \frac{\left(f\left(U_{i 2}\right)-f\left(U_{i 1}\right)\right) p^{\prime}\left(G_{S P}^{*}\right)}{p f^{\prime}\left(U_{i 2}\right) U_{i 2}^{\prime}+(1-p) f^{\prime}\left(U_{i 1}\right) U_{i 1}^{\prime}}>1
$$

is fulfilled, we must have $\tilde{G}_{S P}^{*}>G_{S P}^{*}$. As before, the sum of the marginal willingness to pay in this more risk-averse society exceeds the additional cost for unit of $G$ at the level $G_{S P}^{*}$

For both self-insurance and self-protection cases, increasing risk aversion leads to a higher efficient level of the public good. Naturally, this result also means that when the individuals become less risk-averse, the efficient provision level of public self-insurance decreases. This will be an important case in the following sections.

\section{Efficient provision with market insurance}

Following Ehrlich and Becker (1972), we will analyze the efficient provision level (and later the optimal individual choice) if both market insurance and self-insurance or self-protection are available, the latter two as public goods. We assume that individual $i$ can buy coverage $s_{i} \in[0, L]$ at a uniform price $\pi$ and can contribute to the public device $G$ at the marginal cost of 1 . For coverage $s_{i}$, a premium of $\pi s_{i}$ has to be paid. Since we want to concentrate on the relationship between public insurance through the public good and private market insurance, we assume that market insurance is fair; i. e., the insurance premium equals the expected loss. Our results carry over with only quantitative changes if we assume a positive loading factor when buying insurance.

\subsection{Efficient provision of self-insurance}

Since the individuals have the possibility to insure the loss at a fair premium, a risk averse subject will always choose to buy full insurance, where fair insurance means $\pi=p$. The resulting utility level is given by

$$
U_{i}\left(g_{i}\right)=U\left(m_{i}-g_{i}-p L(G)\right), \quad \text { for } i=1, \ldots, n \text {. }
$$


Efficient public self-insurance can be derived by maximizing the following Lagrangian:

$$
\mathcal{L}=U_{1}+\sum_{j=2}^{n} \mu_{j}\left(U_{j}-\bar{U}_{j}\right)+\lambda\left(G-\sum_{i=1}^{n} g_{i}\right)
$$

and the first-order conditions with respect to $G$ and $g_{i}$ are given by

$$
\begin{aligned}
& \frac{\partial \mathcal{L}}{\partial G}=\sum_{j=1}^{n} \mu_{j} p U_{j}^{\prime}\left(-L^{\prime}\left(\hat{G}_{S I}^{*}\right)\right)+\lambda=0 \\
& \frac{\partial \mathcal{L}}{\partial g_{i}}=\mu_{i} U_{i}^{\prime}+\lambda=0, \quad \text { for } i=1, \ldots, n,
\end{aligned}
$$

where $\mu_{1}=1$ and a hat indicates the efficient public good level that is obtained in the presence of private market insurance. Rearranging yields

$$
\sum_{j=1}^{n} \frac{-\lambda}{U_{j}^{\prime}} p U_{j}^{\prime}\left(-L^{\prime}\left(\hat{G}_{S I}^{*}\right)\right)+\lambda=0 .
$$

This leads to the following proposition.

\section{Proposition 4 (Efficient public self-insurance with market insurance)}

If beside public self-insurance fair market insurance is available, the Pareto efficient level of a public good $G$ which acts as a self-insurance device is given by the modified Samuelson condition

$$
n \cdot p\left(-L^{\prime}\left(\hat{G}_{S I}^{*}\right)\right)=1
$$

Condition (29) can be interpreted in a standard way: the left hand hand is the expected marginal benefit of an additional unit of self-insurance, while the right hand side is its marginal cost. However, since $G$ is a public good, the expected marginal benefit $p\left(-L^{\prime}\left(\hat{G}_{S I}^{*}\right)\right)$ accrues to all $n$ individuals and thus has to be multiplied by $n$.

\section{Comparison of efficient provision with and without private insurance}

Since some risks are not insurable (at least, at the individual level) while for some other risks there is readily available private market insurance, it is of practical interest to analyze how the efficient provision level of the public good changes when market insurance is available. Consequently, we wish to compare the efficient public good levels $G_{S I}^{*}$ and $\hat{G}_{S I}^{*}$ resulting from conditions (10) and (29).

On both right hand sides of conditions (10) and (29) we have 1, the marginal cost of an additional unit of public self-insurance. The left hand side of (10) can be written as

$$
p\left(-L^{\prime}\left(G_{S I}^{*}\right)\right) \sum_{i=1}^{n} \frac{U_{i 2}^{\prime}}{E U_{i}^{\prime}} .
$$


As income is lower in state 2, marginal utility $U_{i 2}^{\prime}$ is greater than expected marginal utility, which is the probability average of both marginal utilities. Thus, all the fraction summands are greater than 1, the sum is greater than $n$. Compared to condition (29) above, we obtain

$$
\begin{aligned}
-L^{\prime}\left(G_{S I}^{*}\right) & <-L^{\prime}\left(\hat{G}_{S I}^{*}\right) \\
G_{S I}^{*} & >\hat{G}_{S I}^{*}
\end{aligned}
$$

The availability of private insurance decreases the efficient provision level of the public self-insurance. Given that fair market insurance is available, the individuals behave as if they were risk neutral expected income maximizers. This changes the efficient equilibrium level $G_{S I}$ in the direction established in section 3.2: decreasing risk aversion decreases the efficient provision level of public self-insurance.

\subsection{Efficient provision of self-protection}

In the self-protection case, the individuals analogously choose to buy full fair insurance which leads to utility

$$
U_{i}\left(g_{i}\right)=U\left(m_{i}-g_{i}-p(G) L\right), \quad \text { for } i=1, \ldots, n .
$$

The resulting Lagrangian for this problem is

$$
\mathcal{L}=U_{1}+\sum_{j=2}^{n} \mu_{j}\left(U_{j}-\bar{U}_{j}\right)+\lambda\left(G-\sum_{i=1}^{n} g_{i}\right)
$$

and the first-order conditions with respect to $G$ and $g_{i}$ are

$$
\begin{aligned}
& \frac{\partial \mathcal{L}}{\partial G}=\sum_{j=1}^{n} \mu_{j} U_{j}^{\prime}\left(-p^{\prime}\left(\hat{G}_{S P}^{*}\right) L\right)+\lambda=0 \\
& \frac{\partial \mathcal{L}}{\partial g_{i}}=-\mu_{i} U_{i}^{\prime}-\lambda=0, \quad \text { for } i=1, \ldots, n,
\end{aligned}
$$

where $\mu_{1}=1$. Rearranging terms yields

$$
\sum_{j=1}^{n} \frac{-\lambda}{U_{j}^{\prime}} p U_{j}^{\prime}\left(-p^{\prime}\left(\hat{G}_{S P}^{*}\right) L\right)+\lambda=0,
$$

which leads to the following proposition.

\section{Proposition 5 (Efficient public self-protection with market insurance)}

If beside self-protection fair market insurance is available, then the Pareto efficient level of a public good $G$ which acts as a self-protection device is given by the modified Samuelson condition

$$
n \cdot\left(-p^{\prime}\left(\hat{G}_{S P}^{*}\right)\right) L=1
$$


Condition (37) can be interpreted analogously to the self-insurance case: the left hand hand is the expected marginal benefit of an additional unit of the self-protection public good to the $n$ individuals, while the right hand side is its marginal cost.

\section{Comparison of efficient provision with and without private insurance}

In order to compare the efficient public good levels $G_{S P}^{*}$ and $\hat{G}_{S P}^{*}$ without and with market insurance, we analyze conditions (14) and (37). However, in the self-protection case, we cannot say unambiguously whether the summands in condition (14) are greater or smaller than 1. Consider as a special case the situation where all individuals have equal income; i. e., $m_{i}=m$ for all $i$. Condition (14) can then be rearranged to

$$
n \cdot\left(-p^{\prime}\left(G_{S P}^{*}\right)\right) \frac{U_{i 2}-U_{i 1}}{E U_{i}^{\prime}}=1
$$

which is easy to compare with condition (37). In order to obtain the intuitive result

$$
\begin{aligned}
G_{S P}^{*} & >\hat{G}_{S P}^{*} \\
-p^{\prime}\left(G_{S P}^{*}\right) & >-p^{\prime}\left(\hat{G}_{S P}^{*}\right),
\end{aligned}
$$

we need to have

$$
\begin{aligned}
L & >\frac{\left(U_{i 2}-U_{i 1}\right)}{E U_{i}^{\prime}} \\
E U_{i}^{\prime} & >\frac{U_{i 2}-U_{i 1}}{L}
\end{aligned}
$$

The right hand side of (40) is the slope of the secant on the utility function $u$ through the points $u\left(y_{i 2}\right)$ and $u\left(y_{i 1}\right)$, while the expected marginal utility on the left hand side is the probability average of the slopes of $u$ at the points $u\left(y_{i 2}\right)$ and $u\left(y_{i 1}\right)$. Since the slope of the secant is greater (smaller) than the slope of the tangent at $u\left(y_{i 1}\right)\left(u\left(y_{i 2}\right)\right)$, one cannot say that (40) is fulfilled for all preferences $u$ and probability functions $p$. This result, which we have illustrated for the special case where all individuals have equal income, carries over to the more general case. From section 3.2, we know that decreasing risk aversion decreases the efficient provision level of public self-protection. Yet, as already known from Ehrlich and Becker (1972), the availability of private insurance does not necessarily decreases the optimal level of private self-protection, which also depends on risk preferences and probabilities. 


\section{Private provision of the public good}

Suppose now that there are $n>1$ individuals but no social planner who provides the efficient provision level of the insurance public good $G$. Thus, the individuals contribute privately to the public good. In this setting, we make two assumptions. As usual in most private provision games, we assume Nash behavior, i. e. the individuals take the contributions of the other players as given and react to the others' behavior with their best response. We will denote the resulting equilibrium levels with the superscript $N$ for Nash. Additionally, we make the simplifying assumption that all individuals are rich enough to be contributors, or, alternatively, that income is so evenly distributed such that there are no pure free-riders in our game and all individuals are included in the set of contributors. This assumption means that, in equilibrium, all individuals are at an inner solution and allows us to disregard corner solutions. As a by-product, assuming that all individuals are in the included in the set of contributors excludes the anomaly of overprovision of a public good (see Buchholz and Peters, 2001). This assumption has no effect on our results below and, by greatly simplifying the analysis, allows us to focus on the interaction between the private contributions to the public good and the contributions to market insurance.

\subsection{Private provision of self-insurance}

The maximization problem of the individual is similar to the situation presented in section 2 , where we analyzed the case of $n=1$, with the only difference that now there are $n-1$ additional contributors who already reduce the size of the loss: $G_{-i}^{S I}=\sum_{j=1, j \neq i}^{n} g_{j}^{S I}$ is the sum of the contributions of all other individuals but subject $i$. The derivation resembles closely the standard private provision problem as in the original contribution of Bergstrom et al. (1986), so we skip the calculation and apply the well-known results concerning the private provision level of the public good and its invariance with respect to income redistribution to state directly that the first order condition for individual expected utility maximization is given by

\section{Proposition 6 (Privately provided level of self-insurance)}

The privately provided efficient level of a public good $G$ which acts as a self-insurance device is given by

$$
\frac{p U_{i 2}^{\prime}\left(-L^{\prime}\left(G_{S I}^{N}\right)\right)}{E U_{i}^{\prime}}=1, \quad i=1, \ldots, n
$$


It is independent of the income distribution as long as before and after redistribution all individuals belong to the set of contributors.

This proposition can be proved by the following argument: Our model's uncertainty settings, where the individuals maximize their expected utility, imply that the utility function $U$, in a formal sense, is additively separable. Hence, the demand for both state contingent income levels is strictly normal. Additionally, we have assumed that all individuals contribute. Thus, we can apply the result of Bergstrom et al. (1986) on uniqueness and existence of the private provision equilibrium, and of Warr (1983) regarding redistribution invariance.

\subsection{Private provision of self-protection}

The maximization problem of the individual is very similar to the situation in the preceding section. In an analogous way, the first order condition for individual expected utility maximization is given by

\section{Proposition 7 (Privately provided level of self-protection)}

The privately provided efficient level of a public good $G$ which acts as a self-protection device is implicitly defined by

$$
\frac{\left(-p^{\prime}\left(G_{S P}^{N}\right)\right)\left(U_{i 1}-U_{i 2}\right)}{E U_{i}^{\prime}}=1, \quad i=1, \ldots, n .
$$

It does not depend on the distribution of income as long as before and after redistribution all individuals belong to the set of contributors.

The proof is analogous to the case of privately provided self-insurance.

\subsection{Private provision vs. efficient level}

As usual in private provision games, the contributions to $G_{-i}^{S I}$ and $G_{-i}^{S P}$ by the other players but $i$ represent a de facto income transfer to $i$. While the efficiency conditions (10) and (14) require the sum of the willingness to pay of all individuals to equal the marginal cost of providing the public good, an individually rational contributor only takes into consideration the effect of his contribution on his individual utility, which decreases the resulting equilibrium cases for both self-insurance and self-protection: 


\section{Proposition 8 (Privately provided self-insurance and self-protection)}

The privately provided level of a public good $G_{S I}^{N}$, which acts as a self-insurance device, and the privately provided level of a public good $G_{S P}^{N}$, which acts as a self-protection device, are both smaller than their corresponding Pareto-efficient levels $G_{S I}^{*}$ and $G_{S P}^{*}$.

A proof can be omitted since our assumptions allow us to apply directly the results of of Buchholz and Peters (2001) which exclude the underprovision possibility.

\section{$6 \quad$ Interaction of private provision with market insurance}

\subsection{Market insurance and self-insurance}

The individual $i$ maximizes her expected utility

$$
E U_{i}\left(g_{i}, G, s_{i}\right)=p U\left(m_{i}-g_{i}-L(G)+(1-\pi) s_{i}\right)+(1-p) U\left(m_{i}-g_{i}-\pi s_{i}\right)
$$

by simultaneously choosing $g_{i}$ and $s_{i}$. The first-order conditions are given by

$$
\begin{aligned}
& F O C^{g}:=\frac{\partial E U_{i}}{\partial g_{i}}=p U_{i 2}^{\prime}\left(-1-L^{\prime}\left(\hat{G}_{S I}^{N}\right)\right)+(1-p) U_{i 1}^{\prime}(-1)=0 \\
& F O C^{s}:=\frac{\partial E U_{i}}{\partial s_{i}}=p U_{i 2}^{\prime}(1-\pi)-(1-p) U_{i 1}^{\prime} \pi=0
\end{aligned}
$$

the second-order conditions are fulfilled for $U_{i}^{\prime \prime}<0$ and $L^{\prime \prime}>0$ as assumed. We write $\hat{G}_{S I}^{N}$ for the Nash equilibrium level of the public good in the self-insurance case with market insurance. Conditions (44) and (45) can be rearranged to

$$
\frac{\pi}{1-\pi}=\frac{1}{-1-L^{\prime}\left(\hat{G}_{S I}^{N}\right)}
$$

The optimum is reached when the shadow price of self-insurance, as given by the right hand side, is equal to the market price of insurance (left hand side). In other words, the individual is indifferent whether to spend an additional unit of income in self-insurance or market insurance. If the price for market insurance is fair, $\pi=p$, condition (46) leads to

\section{Proposition 9 (Private provision of self-insurance with market insurance)}

The privately provided efficient level of a public good $G$, which acts as a self-insurance device, in the presence of market insurance is implicitly defined by

$$
\frac{1}{-1-L^{\prime}\left(\hat{G}_{S I}^{N}\right)}=\frac{p}{1-p} \quad \Longleftrightarrow \quad p \cdot\left(-L^{\prime}\left(\hat{G}_{S I}^{N}\right)\right)=1 .
$$


Condition (47) is also the condition that maximizes expected income. However, in contrast to the efficient provision, expected income is maximized at the individual and not at the social level. We can calculate the comparative static effect of $\pi$ on the first-order conditions (44) and (45). Let $D$ be the determinant of the maximization problem (43). By the secondorder condition and our assumptions, we have $D=F O C^{g g} \cdot F O C^{s s}-\left(F O C^{g s}\right)^{2}>0$, where the index denotes the partial derivative(s) with respect to the corresponding variable(s). Then, we obtain by Cramer's rule

$$
\begin{aligned}
& \frac{d g}{d \pi}=\frac{1}{D}\left|\begin{array}{ll}
F O C_{s s} & F O C_{s \pi} \\
F O C_{g s} & F O C_{g \pi}
\end{array}\right|>0 \\
& \frac{d s}{d \pi}=\frac{1}{D}\left|\begin{array}{ll}
F O C_{s \pi} & F O C_{s g} \\
F O C_{g \pi} & F O C_{g g}
\end{array}\right|<0
\end{aligned}
$$

Thus, market insurance and self-insurance are strategic substitutes in the sense that a market price increase in market insurance decreases the demand for market insurance and increases the demand for self-insurance, which has become relatively cheaper.

Condition (47) defines implicitly a private provision level $\hat{G}_{S I}^{N}$ of public self-insurance in the presence of market insurance, which can be compared with the privately provided provision level $G_{S I}^{N}$ without market insurance as given by equation (41):

$$
-L^{\prime}\left(\hat{G}_{S I}^{N}\right)=\frac{1}{p}>\frac{1}{p} \frac{E U_{1}^{\prime}}{U_{12}^{\prime}}=-L^{\prime}\left(G_{S I}^{N}\right)
$$

Since

$$
\frac{E U_{1}^{\prime}}{U_{12}^{\prime}}=\frac{(1-p) U_{11}^{\prime}+p U_{12}^{\prime}}{U_{12}^{\prime}}<1
$$

because the marginal utility in the loss state 2 is larger than in non-loss state $1, U_{12}^{\prime}>U_{11}^{\prime}$. Further,

$$
\begin{aligned}
-L^{\prime}\left(\hat{G}_{S I}^{N}\right) & >-L^{\prime}\left(G_{S I}^{N}\right) \\
\hat{G}_{S I}^{N} & <G_{S I}^{N} .
\end{aligned}
$$

Thus, the possibility of buying market insurance and the strategic substitutability between self-insurance and market insurance decreases the privately provided level of the public good further.

To compare the efficient and the private provision level of self-insurance when market insurance is available, we use conditions (29) and (47). Since the efficiency condition (29) 
contains the size $n$ of the population that benefits from public self-insurance and the private provision condition (47) does not reflect the positive external effect of the public good,

$$
\hat{G}_{S I}^{N}<\hat{G}_{S I}^{*}
$$

Combining results (53) and (54) with proposition 8, we obtain the following ranks of the provision level of the public good:

$$
\begin{gathered}
\hat{G}_{S I}^{N}<G_{S I}^{N}<G_{S I}^{*} \\
\hat{G}_{S I}^{N}<\hat{G}_{S I}^{*}<G_{S I}^{*}
\end{gathered}
$$

\subsection{Market insurance and self-protection}

We calculate the optimal individual behavior in an analogous way. The individual maximizes her expected utility

$$
E U_{i}\left(g_{i}, G, s_{i}\right)=p(G) U\left(m_{i}-g_{i}-L+(1-p(G)) s_{i}\right)+(1-p(G)) U\left(m_{i}-g_{i}-p(G) s_{i}\right)
$$

by simultaneously choosing $g_{i}$ and $s_{i}$, where we have already used the fair insurance condition $\pi=p(G)$. The first-order conditions are given by

$$
\begin{aligned}
\frac{\partial E U_{i}}{\partial s_{i}}= & p\left(\hat{G}_{S P}^{N}\right) U_{i 2}^{\prime}\left(1-p\left(\hat{G}_{S P}^{N}\right)\right)-\left(1-p\left(\hat{G}_{S P}^{N}\right)\right) p\left(\hat{G}_{S P}^{N}\right) U_{i 1}^{\prime}=0 \\
\frac{\partial E U_{i}}{\partial g_{i}}= & p^{\prime}\left(\hat{G}_{S P}^{N}\right)\left(U_{i 2}-U_{i 1}\right)+p\left(\hat{G}_{S P}^{N}\right) U_{i 2}^{\prime}\left(-1-p^{\prime}\left(\hat{G}_{S P}^{N}\right) s_{i}\right) \\
& +\left(1-p\left(\hat{G}_{S P}^{N}\right)\right) U_{i 1}^{\prime}\left(-1-p^{\prime}\left(\hat{G}_{S P}^{N}\right) s_{i}\right)=0 .
\end{aligned}
$$

In the first condition (58), the probabilities cancel out and we obtain $U_{i 1}^{\prime}=U_{i 2}^{\prime}$, i. e., equal income in both states of the world: When insurance is fair, the individuals choose full cover $s_{i}=L$ independently of the additional self-protection effort. Since $U_{i 1}=U_{i 2}$, the second condition simplifies to

$$
-p^{\prime}\left(\hat{G}_{S P}^{N}\right) L=1
$$

Comparing the Nash private provision equilibrium without market insurance as defined by (42) with the corresponding equilibrium when market insurance is available as described by (60) reveals the complexity of self-protection. $\hat{G}_{S P}^{N}$ is smaller than $G_{S P}^{N}$ if

$$
L<\frac{\left(U_{i 1}-U_{i 2}\right)}{E U_{i}^{\prime}} .
$$


Consequently, if the size of the loss is smaller than the difference in utility weighted by the average marginal utility, then market insurance reduces further the private provision level of the public good.

In order to compare the efficient versus the private provision level of self-protection when market insurance is available, conditions (37) and (60) are relevant. It turns out that $\hat{G}_{S P}^{*}$ is unambiguously larger than $\hat{G}_{S P}^{N}$; i. e., the private provision level is inefficiently small.

\section{Conclusion}

Many public goods provide utility to the society only due to an insurance effect of reducing the size or probability of possible losses. Our paper extends the public good literature by characterizing the efficient provision of such public goods. In contrast to the standard framework, efficient provision of public goods is determined by risk preferences in our model where more risk averse societies prefer higher levels of the public good. If a society becomes richer, the efficient provision of the public good decreases for subjects exhibiting decreasing absolute risk aversion. We also analyze the private provision of public goods with the standard result that the provision level is suboptimal.

An interesting aspect of regarding public goods as insurance device is the interaction with market insurance. The presence of market insurance decreases efficient provision of the public good since fully insured subjects behave as if they were risk neutral. The private provision of public goods is also reduced by the availability of market insurance. Overall, a relatively high provision level is efficient for societies which have a high degree of risk aversion or an underdeveloped insurance sector. A further interesting aspect is that the level of the public good will, in general, be observable by insurers. Consequently, in the case of self-protection (i. e., the public good decreases the probability of losses), public goods may be superior to private self-protection activities if moral hazard problems are involved. 


\section{References}

Austen-Smith, D. (1980), "Individual contributions to public goods," Economics Letters, $5: 359-361$.

Bergstrom, T., L. Blume, and H. Varian (1986), "On the private provision of public goods," Journal of Public Economics, 29:25-49.

Buchholz, W. and W. Peters (2001), "The overprovision anomaly of private public good supply," Journal of Economics, 74(1):63-78.

Cornes, R. and T. Sandler (1996), The Theory of Externalities, Public Goods, and Club Goods, Cambridge University Press, Cambridge, 2nd edn.

Cornes, R. C. and T. Sandler (1984), "Easy riders, joint production, and public goods," Economic Journal, 94:580-598.

Dionne, G. and L. Eeckhoudt (1985), "Self-insurance, self-protection and increased risk aversion," Economics Letters, 17:39-42.

Ehrlich, I. and G. S. Becker (1972), "Market insurance, self-insurance, and self-protection," The Journal of Political Economy, 80(4):623-648.

Gradstein, M., S. Nitzan, and S. Slutsky (1993), "Private provision of public goods under price uncertainty," Social Choice and Welfare, 10:371-382.

Ihori, T. and M. C. McGuire (2007), "Collective risk control and group security: The unexpected consequences of differential risk aversion," Journal of Public Economic Theory, forthcoming.

Mossin, J. (1968), "Aspects of rational insurance purchasing," Journal of Political Economy, 76:553-568.

Orszag, P. and J. Stiglitz (2002), "Optimal fire departments: Evaluating public policy in the face of externalities," Brookings Working Paper.

Pratt, J. W. (1964), "Risk aversion in the small and in the large," Econometrica, 32:122136.

Samuelson, P. A. (1954), "The pure theory of public expenditure," Review of Economics and Statistics, 36:387-389. 
Samuelson, P. A. (1955), "Diagrammatic exposition of a theory of public expenditure," Review of Economics and Statistics, 37:350-356.

Sandler, T., F. P. Sterbenz, and J. Posnett (1987), "Free riding and uncertainty," European Economic Review, 31:1605-1617.

Warr, P. G. (1983), "The private provision of public goods is independent of the distribution of incomes," Economic Letters, 13:207-211. 